\title{
A Study of Below Knee Surrounding Dose depends on whether Using Collimator Shielding or not while Percutaneous Coronary Intervention
}

Jae Jin Park, Seong Jin Ko, Se Sik Kang, Chang Soo Kim, Jung Hoon Kim, Dong Hyun Kim

Pusan catholic University

\section{경피적 관상동맥 중재술 시 차폐 유 · 무에 따른 슬 하부 주변부 선량에 관한 연구}

박재진, 고성진, 강세식, 김창수, 김정훈, 김동현

부산가톨릭대학교

\begin{abstract}
Recently, the Percutaneous Coronary Intervention has become a main treatment for treating Coronary because of increase of Circulatory Disease. Because of this reason, the increase of intervention using radiation causes the radiation exposure to workers. Therefore, the latent radiation injury can be increased. Thus, this study/experiment measured around under knee whether using radiation collimator shielding or not. We measured the exposure does by the experiment methods which are using $60 \mathrm{kV}, 200 \mathrm{~mA}$, and $10 \mathrm{~ms}$ of Automatic exposure conditions and using the major method of the Cinefluography of Coronary in our hospital. As the result of right coronary artery test cases, LAO $30^{\circ}$ when the curtains if you use lead $98.4 \%$, Cranial $30^{\circ}$ 98.3\% have a protective effect of the radiation. left circumflex coronary artery test cases, Caudal $30^{\circ}$ if the shielding effect of $90.2 \%$, Caudal $30^{\circ} \mathrm{LAO} 30^{\circ} 88.7 \%$ have a protective effect of the radiation. left anterior descending artery test cases, Cranial $30^{\circ} 98.3 \%$, Cranial $30^{\circ} \mathrm{RAO} 30^{\circ} 80.3 \%$, Cranial $30^{\circ} \mathrm{LAO} 30^{\circ} 98 \%$ of the radiation has a protective effect. OS(Spider view) in the case of test Caudal $40^{\circ} \mathrm{LAO} 40^{\circ} 71.2 \%$ appeared to have the effect of radiation shielding. For these reasons, radiation workers need to be aware on taking care of their radiation exposure by using the radiation collimator shielding even though it is uncomfortable for them.
\end{abstract}

Key Words : Percutaneous Coronary Intervention, Surrounding Dose, Exposure Dose

\section{요 야}

최근 순환기계 질환이 증가함에 따라 경피적 관상동맥 중재술이 관상동맥 치료에 주된 치료 방법으로 사용되고 있 다. 이러한 이유로 방사선을 이용하는 중재술이 증가함에 따라 작업종사자의 방사선피폭을 증가되고 그에 따른 잠재적 방사선 장해를 증가 시킬 수가 있을 것이다. 이에 본 연구에서는 방사선 차폐체인 납 커튼 유·무에 따른 슬 하부 주변 선량을 측정하였다. 실험방법은 자동노출조건 $60 \mathrm{kV}, 200 \mathrm{~mA}, 10 \mathrm{mS}$ 을 이용하여 본원에 주로 사용되는 관상동맥 촬영 방법을 이용하여 슬 하부 주변부 선량을 측정하였다. 결과로는 right coronary artery 검사 시, LAO $30^{\circ}$ 을 경우 납 커튼 사용 유·무에 따른 방서선 방어효과는 $98.4 \%$, Cranial $30^{\circ} 98.3 \%$ 효과를 가진다. left circumflex coronary artery 검사 시, 
Caudal $30^{\circ}$ 을 경우 납 커튼 사용 유·무에 따른 방사선 방어효과는 $90.2 \%$, Caudal $30^{\circ} \mathrm{LAO} 30^{\circ} 88.7 \%$ 의 효과를 가진다. left anterior descending artery 검사 시, Cranial $30^{\circ}$ 을 경우 납 커튼 사용 유·무에 따른 방사선 방어효과는 $98.3 \%$, Cranial $30^{\circ} \mathrm{RAO} 30^{\circ} 80.3 \%$, Cranial $30^{\circ} \mathrm{LAO} 30^{\circ} 98 \%$ 의 효과를 가진다. OS(Spider view) 검사 시, Caudal $40^{\circ} \mathrm{LAO} 40^{\circ}$ 을 경우 납 커튼 사용 유·무에 따른 방사선 방어효과는 $71.2 \%$ 의 효과를 가지는 것으로 나타났다. 이러한 이유로 방사선 작업종사 자의 경우 방사선 차폐 보조기구를 사용을 불편하더라도 가능한 방사선 차폐도구를 이용함으로써 자신의 방사선 피폭 관리에 관심을 기울려야 할 것이다.

중심단어: 경피적 관상동맥 중재술, 주변부선량, 피폭선량

\section{I. 서 론}

현대사회는 노령인구의 증가, 서구화된 식생활 습 관, 비만, 운동부족 등 여러 가지 이유로 인해 심근경 색등 순환기계통의 질환이 빠르게 증가하고 있는 추 세이다.

미국심장협회(American heart association, 2005)에 따 르면 미국에서의 사망률 1 위가 여전히 순환기계 질환 임을 확인되었고, 한국에서도 순환기계 질환의 사망률 이 인구 10 만 명당 순환기계통 사망률이 113.5 명으로 2010년 대비 2011년 $0.9 \%$ 증가하였다 ${ }^{[1][2]}$.

이러한 변화로 추세로 인해 과거의 관상동맥 질환 치료 방법은 주된 치료방법은 약물요법과 외과적 수 술인 관상동맥 우회술이 대중적인 치료 방법이었으나, 현재의 관상동맥질환의 발전은 1977년 9월 16일 최초 로 Andreas Gruentzig가 풍선을 통해 혈관으로 접근한 경피적 관상동맥 중재술 (percutaneous coronary intervention, $\mathrm{PCI}$ 성공을 통해서 급속하게 관상동맥 질 환의 주된 치료방법으로 변화 되었다.

최근에는 기자재의 발달, 시술자의 경험 축적, Stent 를 포함한 여러 치료기구들의 개발, 시술 대상의 확대, 재 협착에 대한 병태생리연구, 임상연구 활동, 새로운 항 혈소판 약제의 사용 등으로 인하여 치료 성적에 괄 목할 만한 성장을 거듭했다 ${ }^{[3]}$.

하지만 경피적 관상동맥 중재시술의 발달은 긍정적 인 효과만을 증가시킨 것은 아니다. 경피적 관상동맥 중재술은 전리 방사선을 이용하기 때문에 작업종사자 와 환자에게 많은 이익을 주기도 하지만 단편적으로 는 방사선을 이용한 작업종사자와 환자에게는 방사선 의 피폭을 증가시켰다 ${ }^{[4][5]}$. 특히 경피적 관상동맥 중재 술의 경우 디지털 혈관 영화 촬영을 이용하여 긴 시간
동안 시술을 진행하기 때문에 다른 의료방사선 피폭 보다는 작업종사자와 환자에게 많은 방사선 피폭을 노출시키는 시술방법이다.

작업종사자의 경우 방사선 작업상의 주된 피폭은 조사야 내에 인체를 넣어서 조작해야하는 상황을 제 외하고는 주위에서 발생되는 방사선의 피폭은 산란선 에 의한 것이다. 산란선의 발생원은 X-선관 장치전면 의 가동 조리개 및 $\mathrm{X}$-선관 누설선량 그리고 환자의 몸 이다. 여러 산란선의 발생원 중 테이블 아래에서 가장 많은 발생된다고 보고되고 있다[6]. 이는 작업종사자의 생식선과 다리에 피폭이 많다는 것을 의미하며, 생식 선의 경우 착용하고 있는 방호용구로 대부분 방사선 에 의한 차폐가 가능하다. 하지만 경골과 대퇴골에는 적색골수가 많이 존재하며, 적색골수의 피폭은 백혈병의 원인이 되는 점에서 유효하게 차폐할 필요 하겠다 ${ }^{[7]}$.

이에 본 연구에서는 많은 중재방사선 절차에 걸리 는 장시간의 조사 시간 때문에 작업종사자의 직업상 피폭을 높일 잠재성이 있다고 보고되고 있다. 본 연구 에서는 산란선이 가장 많이 발생되면 주변 방사선 방 어보호구를 사용에 제약이 되는 슬 하부 주변부 선량 을 파악하였다. 그리고 추가적으로 슬 하부 방사선 차폐도구인 납 커튼을 이용하여 방사선의 차폐정도를 파악하여 방사선의 차폐체가 방사선 작업종사자 에 게 얼마만큼의 피폭을 줄 일수 있는 정보를 제공하기 위함이다. 


\section{II. 재료 및 방법}

\section{1. 연구방법}

\section{$1.1 \mathrm{X}$-선 발생장치}

본 연구에 사용된 X-선 발생장치로는 Charge Coupled Device 방식(Allura 15, Philips, USA)을 사용하 였다. 촬영조건으로는 자동노출조건 $60 \mathrm{kV}, 200 \mathrm{~mA}$, $10 \mathrm{mS}$ 을 조사 하였다.[Fig. 1]

\section{2 모의 피폭체}

X-선 Water phantom은 인체의 X-선 흡수 및 산란에 거의 근사한 효과를 나타내는 물을 주체로 하여 구성 된 물질로써 산업통상부 기술 표준원의 기준을 바탕 으로 $55 * 30 * 25$ 흉부Water phantom을 제작 하였다. 이 규격은 X-선 장치 또는 관련기기의 조정, 시험 및 X선 측정 등에 사용하는 X-선 흡수체, $\mathrm{X}$ 선 산란체로서 인 체의 흥부, 복부 해동되는 $\mathrm{X}$ 선 물 팬텀이다 ${ }^{[8]}$ [Fig. 1]

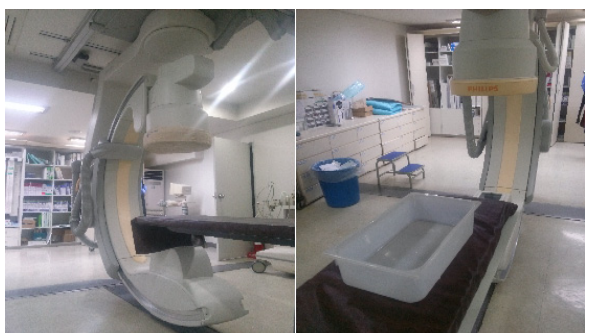

Fig. 1. Exposure to $\mathrm{X}$-ray generator and simulated body

\section{$1.3 \mathrm{X}$-선 선량측정기}

미국SE사의 inspector-SE international 제품으로써 교 정일자가 2013.01.21로써 공간 방사선인 $\delta$-선 뿐만 아 니라, $a$-선, $\beta$-선, $X$-선의 측정이 가능한 측정기를 사용 했다 ${ }^{[9]}$.[Fig. 2]

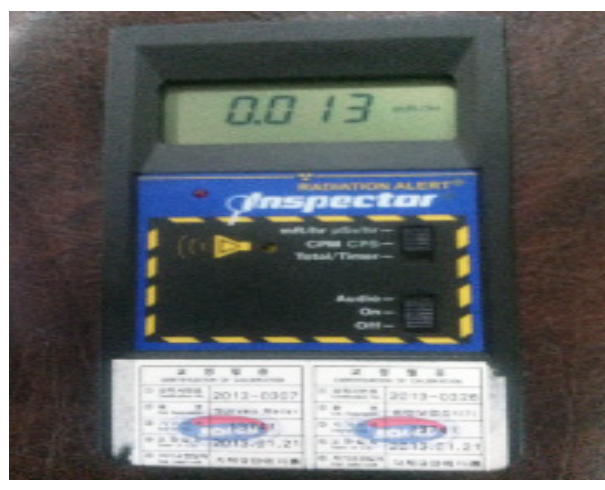

Fig. 2X-ray dose meter

\section{2. 실험방법}

\section{1 측정기 위치 설정}

$\mathrm{X}$-선의 주변선량 측정기의 위치는 방사선 방어 앞 치마를 착용 할 수 없는 슬하 부에 측정기를 위치하여 주변부 선량을 측정한다.

\section{2 측정방법}

본원에서 시행되고 있는 경피적 관상동맥 시술이 적용되는 조건을 이용하여 10 회 반복 측정하여 평균 과 표준편차 값을 측정한다 ${ }^{[10]}$.

그리고 $0.5 \mathrm{mmpb}$ 납 커튼 $(\mathrm{s} / \mathrm{n}: 017637 / 6$, KENEX, GERMANY) 사용하여 동일한 조건으로 반복 측정한 다. [Table 1]

Table 1. Exposure Conditions

\begin{tabular}{|c|c|c|c|}
\hline Coronary & Angle & Time & SSD \\
\hline \multirow{2}{*}{$\mathrm{RCA}$} & LAO $30^{\circ}$ & $5 \mathrm{sec}$ & $120 \mathrm{~cm}$ \\
\hline & Cranial $30^{\circ}$ & $5 \mathrm{sec}$ & $120 \mathrm{~cm}$ \\
\hline \multirow[b]{2}{*}{ LCX } & Caudal $30^{\circ}$ & $6 s e c$ & $120 \mathrm{~cm}$ \\
\hline & $\begin{array}{c}\text { Cauda| I } 30^{\circ} \quad \text { LAO } \\
30^{\circ}\end{array}$ & $6 \mathrm{sec}$ & $120 \mathrm{~cm}$ \\
\hline \multirow{3}{*}{$\angle A D$} & Cranial $30^{\circ}$ & $5 \mathrm{sec}$ & $120 \mathrm{~cm}$ \\
\hline & Cranial $30^{\circ} \quad \mathrm{RAO} 30^{\circ}$ & $5 \mathrm{sec}$ & $120 \mathrm{~cm}$ \\
\hline & Cranial $30^{\circ} \quad \angle A 030^{\circ}$ & $5 \mathrm{sec}$ & $120 \mathrm{~cm}$ \\
\hline $\begin{array}{l}\text { Spider } \\
\text { view }\end{array}$ & Caudal $40^{\circ} \quad \angle A 40^{\circ}$ & $4 \mathrm{sec}$ & $120 \mathrm{~cm}$ \\
\hline
\end{tabular}




\section{III. 결 과}

\section{Right coronary artery(RCA) 검사에 따른 선 량계 측정치}

$\mathrm{RCA}$ 검사의 경우 2 가지의 검사 방법을 용하여 검 사를 시행하였다. 2 가지 검사 방법 모두 10 회 반복 측 정하여 평균치와 표준편차 값을 나타났다.

$\mathrm{LAO} 30^{\circ}$ 평균조사시간을 $5 \mathrm{sec}$ 로 고정한 경우의 방 사선 차폐체인 납 커튼을 사용하지 않았을 경우, $85.2 \mu$ $\mathrm{Sv}$, 표준편차 $1.24 \mu \mathrm{Sv}$, 방사선 납 커튼을 사용했을 경우 $1.3 \mu \mathrm{Sv}$, 표준편차 $0.16 \mu \mathrm{Sv}$ 측정치를 나타났다.

Cranial $30^{\circ}$ 평균조사시간을 $5 \mathrm{sec}$ 로 고정한 경우의 방 사선 차폐체인 납 커튼을 사용하지 않았을 경우, $93.5 \mu$ $\mathrm{Sv}$, 표준편차 $1.36 \mu \mathrm{Sv}$, 방사선 납 커튼을 사용했을 경우 $1.6 \mu \mathrm{Sv}$, 표준편차 $0.2 \mu \mathrm{Sv}$ 측정치를 나타났다.[Fig. 3]

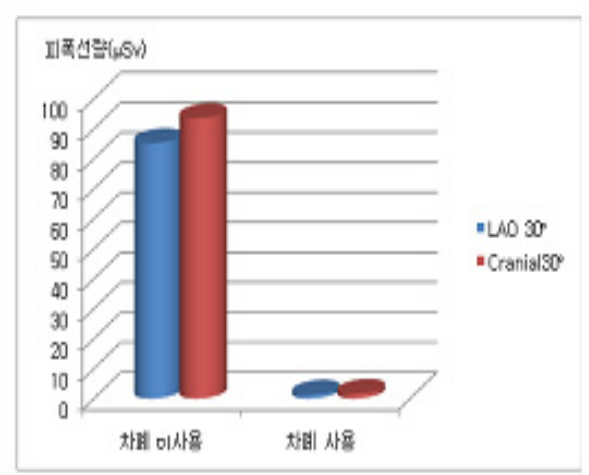

Fig. 3. According to whether you are using curtain dose of lead (RCA)

\section{Left circumflex artery $(\mathrm{LCX})$ 검사에 따른 선 량계 측정치}

$\mathrm{LCX}$ 검사의 경우 2 가지의 검사 방법을 용하여 검 사를 시행하였다. 2 가지 검사 방법 모두 10 회 반복 측 정하여 평균치와 표준편차 값을 나타났다.

Caudal $30^{\circ}$ 평균조사시간을 $6 \mathrm{sec}$ 로 고정한 경우의 방 사선 차폐체인 납 커튼을 사용하지 않았을 경우, 110.4 $\mu \mathrm{Sv}$, 표준편차 $1.29 \mu \mathrm{Sv}$, 방사선 납 커튼을 사용했을 경 우 $10.8 \mu \mathrm{\mu v}$, 표준편차 $0.17 \mu \mathrm{Sv}_{\mathrm{v}}$ 측정치를 나타났다.
Caudal $30^{\circ} \mathrm{LAO} 30^{\circ}$ 평균조사시간을 $6 \mathrm{sec}$ 로 고정한 경우의 방사선 차폐체인 납 커튼을 사용하지 않았을 경우, $100.8 \mu \mathrm{Sv}$, 표준편차 $1.56 \mathrm{\mu Sv}$, 방사선 납 커튼을 사 용했을 경우 $11.3 \mu \mathrm{Sv}$, 표준편차 $0.18 \mu \mathrm{Sv}_{\mathrm{v}}$ 측정치를 나타 났다.[Fig.4]

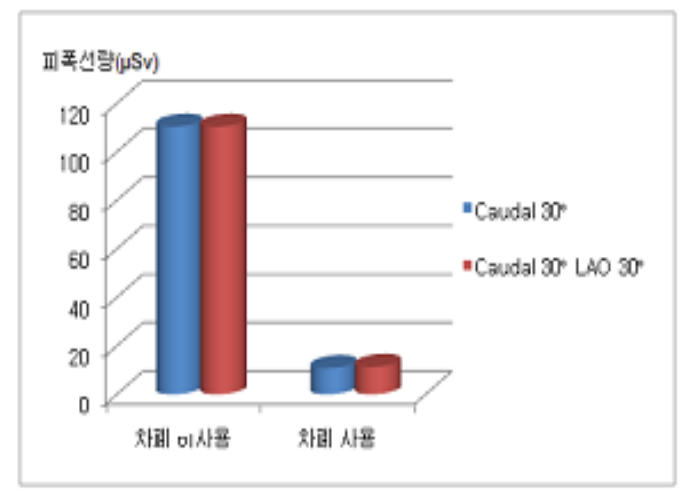

Fig. 4. According to whether you are using curtain dose of lead (LCX)

\section{3. left anterior descending artery(LAD)검사에 따른 선량계 측정치}

$\mathrm{LAD}$ 검사의 경우 3 가지의 검사 방법을 용하여 검 사를 시행하였다. 3 가지 검사 방법 모두 10 회 반복 측 정하여 평균치와 표준편차 값을 나타났다.

Cranial $30^{\circ}$ 평균조사시간을 $5 \mathrm{sec}$ 로 고정한 경우의 방 사선 차폐체인 납 커튼을 사용하지 않았을 경우 93.51 $\mu S_{v}$, 표준편차 $1.66 \mu S_{v}$, 방사선 납 커튼을 사용했을 경 우 $1.6 \mu \mathrm{Sv}$, 표준편차 $0.19 \mu \mathrm{Sv}$ 측정치를 나타났다.

Cranial $30^{\circ} \mathrm{LAO} 30^{\circ}$ 평균조사시간을 $6 \mathrm{sec}$ 로 고정한 경우의 방사선 차폐체인 납 커튼을 사용하지 않았을 경우, $79.4 \mu \mathrm{Sv}$, 표준편차 $2.1 \mu \mathrm{\mu Sv}$ 방사선 납 커튼을 사용 했을 경우 $1.4 \mu \mathrm{Sv}$, 표준편차 $0.31 \mu \mathrm{S}_{\mathrm{v}}$ 측정치를 나타났다.

Cranial $30^{\circ} \mathrm{RAO} 30^{\circ}$ 평균조사시간을 $5 \mathrm{sec}$ 로 고정한 경우의 방사선 차폐체인 납 커튼을 사용하지 않았을 경우, $65.4 \mu \mathrm{Sv}$, 표준편차 $1.54 \mu \mathrm{Sv}$ 방사선 납 커튼을 사 용했을 경우 $1.3 \mu \mathrm{Sv}$, 표준편차 $0.35 \mu \mathrm{Sv}$ 측정치를 나타 났다.[Fig.5] 


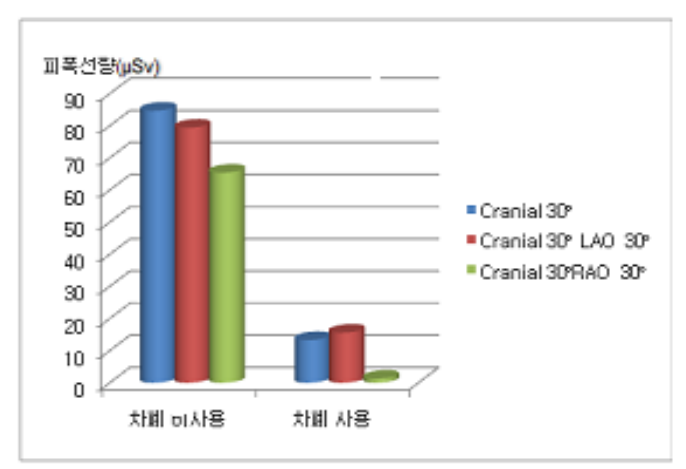

Fig .5 According to whether you are using curtain dose of lead (LAD)

\section{OS(Spider view) 검사에 따른 선량계 측정치}

Spider view 검사의 경우 1 가지의 검사 방법을 이용 하여 검사를 시행하였다. 1 가지 검사 방법을 10 회 반 복 측정하여 평균치와 표준편차 값을 나타났다.

Caudal $40^{\circ} \mathrm{LAO} 40^{\circ}$ 평균조사시간을 $4 \mathrm{sec}$ 로 고정한 경우의 방사선 차폐체인 납 커튼을 사용하지 않았을 경우, $100.4 \mu \mathrm{Sv}$, 표준편차 $1.23 \mu \mathrm{Sv}$, 방사선 납 커튼을 사용했을 경우 $28.9 \mu \mathrm{Sv}$, 표준편차 $0.58 \mu \mathrm{Sv}$ 측정치를 나 타났다.[Fig.6]

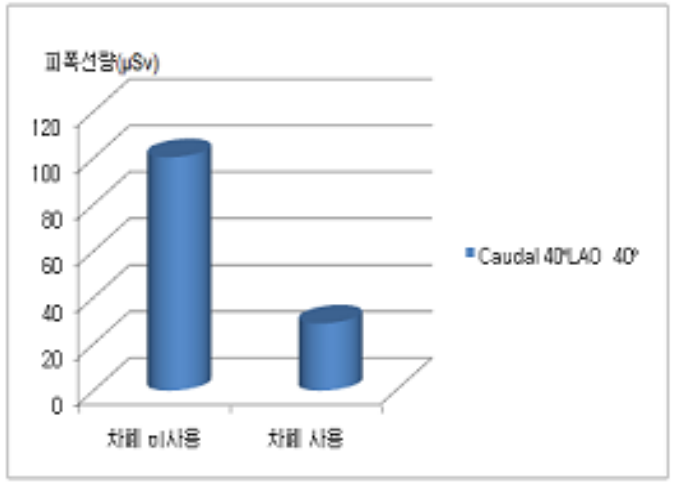

Fig. 6. According to whether you are using curtain dose of lead(OS)

\section{$\mathrm{IV}$. 고 찰}

의료기술이 발전함에 따라 경피적 관상동맥 중재적 시술의 적용 범위도 계속적으로 확대되고 있다. 주로 중재적 시술의 경우 연속적인 영상을 보면서 중재적
시술하므로 환자와 작업종사자가 상당시간 노출됨으 로 자칫 방사선 장해와 같은 부작용을 발생하기 쉽다 [11]. 이에 본 연구에서는 경피적 관상동맥 중재적 시술 중 방사선 방어 앞치마를 착용하지 못하는 슬 하부에 많은 피폭을 받을 것으로 예상되어 Tube의 각도 변화 에 따라 슬 하부 주변선량을 알아보았다.

$\mathrm{RCA}$ 검사의 경우 $\mathrm{LAO} 30^{\circ}$ 을 경우 납 커튼을 사용 했을 경우 $98.4 \%, \mathrm{Cranial} 30^{\circ} 98.3 \%$ 의 방사선 방어 효과 를 가진다. LCX 검사의 경우 Caudal $30^{\circ}$ 을 경우 차폐 효과는 $90.2 \%$, Caudal $30^{\circ}$ LAO $30^{\circ} 88.7 \%$ 의 방사선 방 어 효과를 가진다. $\mathrm{LAD}$ 검사의 경우 Cranial $30^{\circ} 98.3 \%$, Cranial $30^{\circ}$ RAO $30^{\circ} 80.3 \%$, Cranial $30^{\circ}$ LAO $30^{\circ} \quad 98 \%$ 의 방사선 방어 효과를 가진다. OS(Spider view) 검사의 경우 Caudal $40^{\circ} \mathrm{LAO} 40^{\circ} 71.2 \%$ 의 방사선 방어 효과를 가졌다. 하지만 OS(Spider view)의 경우 Caudal $10^{\circ} \mathrm{LAO}$ $10^{\circ}$ 의 증가에 따란 $88.7 \%$ 에서 $71.2 \%$ 로 $17.5 \%$ 로 차이가 나는 이유는 tube의 각의 증가함에 산란선의 증가로 인해 주변선량의 증가를 시겼다 ${ }^{[12]}$.

중재적 시술 시 받는 피폭선량은 소량의 방사선량 으로 그 영향은 소량 방사선의 생물학적 효과로, 소량 방사선의 생물학적 효과는 암 발생, 돌연변이 발생, 기 형 발생으로 크게 분류 할 수 있으며 BEIR III 보고서 에 의하면 방사선 피폭의 주된 위험성은 암 발생으로 암 발생에 역치가 없는 일-이차모형을 뒷받침하는 상 당한 증거를 제시하고 있다. 이모형 에 의하면 낮은 수준의 방사선 피폭에서 암 발생 위험도는 서서히 증 가하다가 수 Rem 이상의 피폭에서는 급격히 증가하는 것으로 되어 있다 ${ }^{[13]}$.

국제 방사선 방어위원회에서는 방사선 방어에 관한 많은 권고를 하고 있는데 ICRP26에 따른 방사선 방어 의 목표는 “방사선 피폭에 의한 결정적 영향의 발생을 방지하고 확률적 영향의 발생확률을 합리적으로 달성 할 수 있는 한 낮게 유지한다.”이다. 방어의 목표에서 언급하고 있는 “합리적으로 달성할 수 있는 한 낮게” 라는 서술은 이른바 ALARA(As Low As Reasonably Achievable)라고 불리는 방사선 방어의 개념이다. 이는 “정해진 선량당량 한계를 절대로 초과해서는 안 되는 조건을 지키면서 모든 것에 정당화 할 수 있는 피폭을 경제적 사회적 요인을 고려하여 합리적으로 달성할 수 있는 한 낮게 유지하는 것”을 의미한다. 즉, 환자 
개인 및 집단의 방사선 피폭선량은 방사선 진료의 가 치를 손상하지 않는 범위 내에서 최소한으로 하는 것 을 원칙으로 한다 ${ }^{[14]}$.

본 논문에서는 주로 검사하는 촬영 조건은 본원에 서 주로 많이 시행하는 검사 방법을 바탕으로 연구를 진행하였기 때문에 선량 측정의 한계가 남았다. 다양 한 X-선관의 tube 방향을 이용한 선량 측정을 하지 못 한 한계점이 아쉬움으로 남았다.

\section{$\mathrm{V}$. 결 론}

본 연구에서 경피적 관상동맥 시술시 작업종사자의 슬 하부 주변부 선량은 약 $80 \sim 120 \mu \mathrm{Sv}$, 납 커튼을 이용 하여 차폐했을 경우 약 $10 \sim 30 \mu \mathrm{Sv}_{\mathrm{v}}$ 로 차폐효과는 $70 \sim$ $90 \%$ 이상의 차폐효과를 가질 수가 있다. 물론 경피적 관산동맥 시술만으로 받는 선량이 확률적, 결정적인 영향을 일으킬 정도로 많은 양은 아니지만 검사 시간 이 늘어나거나 시술 횟수의 증가로 선량은 기하급수 적으로 증가할 것이다.

비록 슬 하부 주변부의 경우 방사선 감수성은 높지 는 않지만 시술 시 작업종사자가 무시할만한 적은 선 량이 아니기 때문에 방사선 작업종사자는 방사선 차 폐 보조기구를 사용을 불편하더라도 가능한 방사선 차폐도구를 이용함으로써 자신의 방사선 피폭관리에 관심을 기울려야 할 것이다.

따라서 경피적 관상동맥 중재적 시술 중에 시간 적 · 공간적 제약을 받을 지라도 슬 하부의 방사선 피 폭을 방지하기 위하여 방사선 보호구인 납 커튼을 사 용하는 습관을 길러 피폭선량 감소를 시켜야 할 것이 다.

\section{참고문헌}

[1] Cho EH, "Patient's disease related knowledge and education request after Percutaneous Coronary Intervention" Hanyang University, 2009.

[2] Statistics Korea, "Cause of Death Statistics 2011", 2012.

[3] AN TH, "Role of Stent", CURRENT PRACTICE IN CARDIOLOGY Vol.4 (No.8) August, 2010.

[4] Pantos I, Patatoukas G, Katritsis DG, Efstatho poulous E, "Patient radiation dose interventional cardiologry proocedures"
Curr Cardiol Rev; 5:1-11, 2009.

[5] Morrish OW, Goldstone KE, "An investigation in to patient and staff doses from X-ray angiography during coronary interventional procedures, Br J Radiol 008;81:35-45.

[6] Virginia Tsapaki, Sophia Kottou, Eliseo Vano et al "Occupational Dose Constraints in Interventional Cardiology Procedure" Procedure, Phys. Med. 49;997-1005, 2004.

[7] Donald L. Miller, Stephen Balter, Patricia E. etal "Radiation Doses in Interventional Radiology Procedures" JVIR, 14(6), 711-727, 2003

[8] Sin SG, "Comparison of Exposure dose according to the C-arm Angle Change" JOURNAL OF THE KOREA CONTENTS ASSOCIATION Vol.11 No9 pp.453-458, 2011.

[9] KATS New industry standards, "X-ray water phantom for chest and abdomen" 2002,

[10] Park SM "Upon inspection of the patient and the practitioner Coronary Angiography Study on Radiation Dose" Journal of Interventional Imaging Technology Vol.14 No.1 143p 150p, 2011.

[11] "Avoidance of radiation injuries frommedical interventional procedures", ICRP Publication 85.

[12] Jo PG, "Distribution of the Scatter Ray in Fluoroscopy X-ray Room" JOURNAL OF THE KOREA CONTENTS ASSOCIATION) Vol.11 No10 pp.349-354, 2011.

[13] BEIR-V, "Health Effects of Exposure to Low Levels of Ionizing Radiation. Committee on the Biolgical Effects of Ionizing Radiations, Board on Radiation Effects Research, Commission on Life Sciences National Research Council" National Academy Press, Washington. D. C. 1990.

[14] ICRP Publication 26. 